\title{
Changes of partitioning and increased root lengths of spruce and beech exposed to ambient pollution concentrations in southern England
}

\author{
G. Taylor ${ }^{1 *}$, M.C. Dobson ${ }^{2}$ and P.H. Freer-Smith ${ }^{2}$ \\ 1 Division of Biology, University of Lancaster, Lancaster LA1 4YQ, and \\ 2 Forestry Commission, Alice Holt Lodge Farnham, Surrey GU10 4 LH, U.K.
}

\section{Introduction}

Much circumstantial evidence exists to suggest that drought may act as an inciting factor, accelerating the decline of forest trees exposed to chronic doses of air pollution. For instance, many reports suggest that major increases in the decline of spruce occurred after hot and dry summers in Germany. Similarly, Ling and Ashmore (1987) suggested that for beech, loss of green leaves, production of small leaves and altered patterns of shoot growth were amongst the symptoms associated with the decline of this species.

Experimental work on trees in controlled environments has shown that exposure to gaseous pollution may increase susceptibility to drought in at least 2 ways. Firstly, stomatal behaviour may be altered, causing both decreases and increases in water loss (Mansfield and Freer-Smith, 1984) and, secondly, partitioning between roots and shoots may be altered such that the allocation of biomass to roots is restricted (U.K. TERG, 1988). Extrapolation of such results to the field, in particular, to large trees is unwise, since the concentrations used in such experiments are generally in excess of those experienced presently in rural Britain, and the fumigations are often conducted over extremely short time periods on a limited number of small trees. In addition, little research in Britain has focussed on drought and $\mathrm{O}_{3}$, which are known to occur together during summer months, particularly in southern England.

The Forestry Commission has recently developed 3 rural sites, each with 16 open top chambers, to study the effects of ambient concentrations of pollution on tree growth and physiology for a period of up to $5 \mathrm{yr}$. The work reported here describes data collected from the southern England site at Headley, Hampshire, where during the 1988 growing season concentrations of $\mathrm{O}_{3}$ reached $85 \mathrm{ppb}$ on at least 5 occasions.

\footnotetext{
*Present address: St. Mary's College, Strawberry Hill, Waldegrave Road, Twickenham TW1 4SX, U.K.
} 


\section{Materials and Methods}

\section{Experiment 1}

Transplants $(2+1)$ of beech (Fagus sylvatica L.) were rooted into $1 \mathrm{~m}$ plastic tubes containing compost. Tubes were sunk into the ground in open top chambers sited at Headley, Hampshire (Willson et al., 1987). Eight chambers were used, 4 which received ambient air filtered through charcoal and 4 which received unfiltered air. Regular measurements of gas exchange were made from May until September 1988 , using field portable instruments.

\section{Experiment 2}

Clonal material of Sitka spruce (Picea sitchensis (Bong) Carr), was also placed into the same chambers during April 1988. Plants were rooted into compost. Measurements of gas exchange (photosynthesis, transpiration and stomatal conductance) were made using a laboratory system (Taylor and Dobson, 1989).
During July 1988 , trees of both species were harvested and, in addition to measurements of dry weight, root lengths were also assessed, using an automated device. For beech, roots were sampled in $10 \mathrm{~cm}$ sections to a depth of $50 \mathrm{~cm}$.

\section{Results and Discussion}

Fig. 1 illustrates the effects of filtering on the rates of stomatal conductance for beech and spruce. For both species, stomatal conductance was restricted for trees grown in unfiltered (polluted) air, compared with the values in filtered (clean) air. Differences between mean values were tested using $t$ tests and showed that this effect was significant on 3 occasions for leaves of beech.

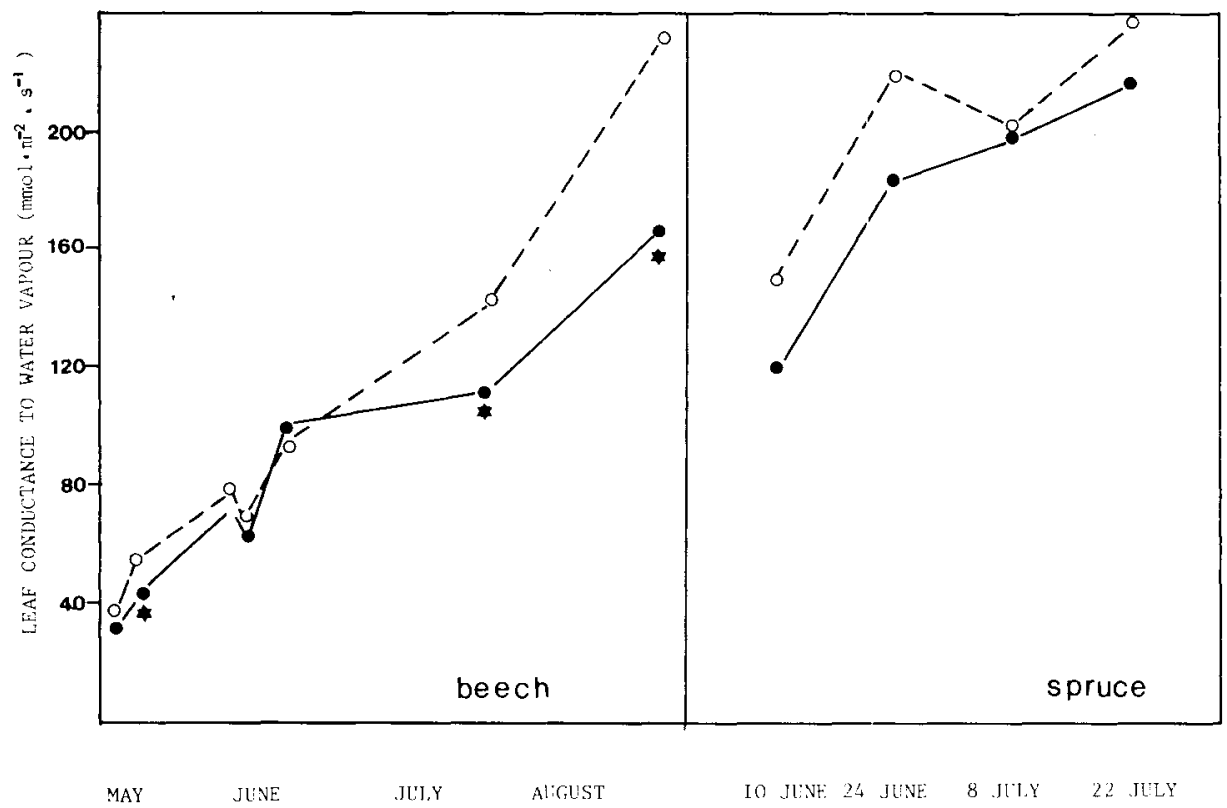

Fig. 1. Stomatal conductance to water vapour of beech and spruce grown in open top chambers and exposed to filtered $(0)$ or unfiltered $(0)$ air. Measurements were made between 11:00-15:00 GMT, minimum ambient temperature during measurement, $19^{\circ} \mathrm{C}$. For beech, each value represents the mean of 36 measurements $(6 /$ chamber), whilst for spruce, each value represents the mean of 4 measurements. Asterisks indicate results of a $t$ test $(P<0.05)$. 
Table I. Root and shoot growth of beech and spruce grown in open top chambers and exposed to filtered or unfiltered air.

\begin{tabular}{|c|c|c|c|c|c|c|c|c|}
\hline \multirow[t]{2}{*}{ Species } & \multicolumn{2}{|c|}{ Root weight (g) } & \multicolumn{2}{|c|}{ Root length $(m)$} & \multicolumn{2}{|c|}{ Specific root length $\left(m \cdot g^{-1}\right)$} & \multicolumn{2}{|c|}{ Root:shoot } \\
\hline & $F$ & UF & $F$ & $U F$ & $F$ & $U F$ & $F$ & $U F$ \\
\hline $\begin{array}{l}\text { Beech } \\
\text { Sitka spruce }\end{array}$ & $\begin{array}{l}4.13 \\
2.12\end{array}$ & $\begin{array}{l}3.52 \\
2.96\end{array}$ & $\begin{array}{l}97.5 \\
23.6\end{array}$ & $\begin{array}{r}129.3^{\star} \\
34.8^{*}\end{array}$ & $\begin{array}{l}26.7 \\
12.1\end{array}$ & $\begin{array}{l}39.3^{\star \star \star} \\
12.3\end{array}$ & $\begin{array}{l}0.571 \\
0.250\end{array}$ & $\begin{array}{l}0.498 \\
0.4000^{\star * *}\end{array}$ \\
\hline
\end{tabular}

F: filtered air; UF: unfiltered air; $n=8$ (beech); $n=4$ (Sitka spruce). ${ }^{*} P<0.05 ;{ }^{* * *} P<0.001$.

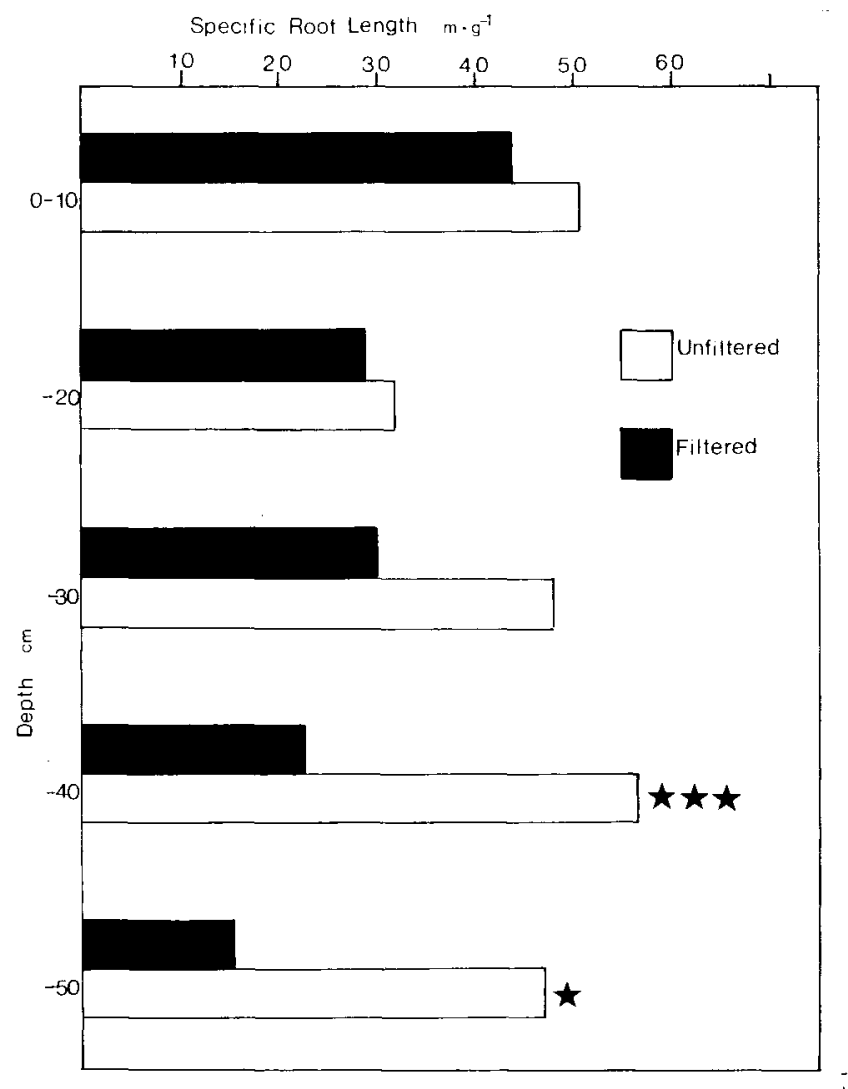

Fig. 2. Specific root length (SRL, length/unit dry weight) of trees grown in filtered or unfiltered air. Data are for beech; asterisks indicate results of a $t$ test $(P<0.05) . n=8$.

Similar effects were also observed for photosynthesis and transpiration, suggesting that ambient concentrations of pollution in southern England may significantly reduce carbon flux to and water loss from shoots of these important species. The conse- 
quences of this consistent decline in gas exchange are shown in Table I and Fig. 2.

As for fumigation studies on small trees (U.K., TERG, 1988), exposure to ambient pollution resulted in reduced root biomass for beech (Table 1). Significant effects on root:shoot ratio were also detected for spruce, such that in the ambient, unfiltered treatment, root:shoot ratio was increased. The most interesting discovery was that reduced biomass of roots was accompanied by increased root length in the unfiltered treatment. Detailed analysis of $S R L$ (root length/unit dry weight) showed that for beech, trees grown in ambient air produced thinner roots (higher $S R L s$ ); this effect was more pronounced lower in the soil profile, perhaps indicating a reduction in primary root growth, relative to the proliferation of the fine root system.

The data suggest that trees grown in unfiltered air could be particularly susceptible to drought-stress, since thinner roots may be prone to loss or turgor and rapid dehydration. In addition, resistance to water flow in such a root system would be particularly high. Conversely, many thin roots may enable the plant to exploit soil moisture and nutrients more effectively during well-watered conditions. Further experimental work is in progress to establish the effects of drought on these trees.

\section{Acknowledgments}

We thank W.J. Davies and T.A. Mansfield for guidance, the D.O.E. for financial support, A. Willson, D.W.H. Durrant and other staff at the Forestry Commission and P. Hutchinson for technical assistance.

\section{References}

Ling K.A. \& Ashmore M.R. (1987) In: Acid Rain and Trees. NCC publication booklet no. 19. Focus on nature conservation

Mansfield T.A. \& Freer-Smith P.H. (1984) The role of stomata in resistance mechanisms. I $m$ : Gaseous Air Pcllutants and Plant Metabolism. (Koziol M.J. \& Whatley F.R., eds.), Butterworths, London, pp. 131-146

Taylor G. \& Dobsson M.C. (1989) Characteristics of photosynthessis, stomatal responses and water relations of Fagus sylvatica: impact of air quality at a site in southern Britain. New Phytol. in press

U.K. Terrestrial E:ffects Review Group (1988) In: The Effects of Acidic Deposition on the Terrestrial Environment in the United Kingdom. Department of Environment, London. pp. 30-31

Willson A., Durrant D.W.H. \& Waddell D.A. (1987) Experimental work on air pollution. Research information note 121.87.SSS, Forestry Commission. 